\title{
SURFACE TEXTURING FOR SILICON SOLAR CELLS USING REACTIVE ION ETCHING TECHNIQUE
}

\author{
G.Kumaravelu', M.M.Alkaisi', A.Bittar ${ }^{2}$ \\ ${ }^{1}$ Department of Electrical and Computer Engineering, University of Canterbury, \\ Private Bag 4800, Christchurch, New Zealand. \\ ${ }^{2}$ Industrial Research Limited, Lower Hutt, Wellington, New Zealand.
}

\begin{abstract}
Surface texturing is an effective and more lasting technique in reducing reflections and improving light trapping compared to antireflection coatings. A surface texturing technique using Reactive lon Etching (RIE) method suitable for crystalline and multi crystalline solar cells, which resulted in surfaces with negligible reflection in the visible band is described.

Different texturing structures (pillars, holes and black silicon) have been studied and compared in the wavelength range from $250 \mathrm{~nm}-2500 \mathrm{~nm}$. It is found that the reflectance of the textured column structures were less than $0.4 \%$ at wavelengths from $500 \mathrm{~nm}$ to $1000 \mathrm{~nm}$ and showed a minimum of $0.29 \%$ at $1000 \mathrm{~nm}$ while the reflectivity from black silicon is around $1 \%$ and hole structures is around $6.8 \%$ in the same wavelength range.
\end{abstract}

\section{INTRODUCTION}

Surface texturing is a more permanent and effective solution to reffection compared to antireflection coating. In addition to minimise reflection of the incoming light, it increases the effective cell thickness through the double bounce effects. Higher cell efficiencies can also be achieved by light trapping of long wavelength light.

Surface texturing for enhanced absorption in Si has been historically obtained by creating randomly distributed pyramids [1] using anisotropic etchants but this works well only on single crystalline silicon because of its crystallographic orientations. These techniques are not satisfactory for multicrystalline silicon (mo-si) solar cells because of the random grain orientation. Several attempts have been made to texture polycrystalline and multi crystalline silicon wafers, including laser-structuring [2], mechanical diamond saw cutting [3] porous-Si etching [4] and mask-less RIE etching which results in so-called "Black silicon" [5]. Also by applying an etch mask to the surface and using isotropic etching, structures can be etched in mc-Si for light confinement [6]

However, most of these generally slow techniques may be too costly to ever be used in large-scale productions. This paper presents hexagonal structured columns and holes texturing using reactive ion etching, which considerably reduces surface reflections and improves light trapping without introducing significant damage [7].

\section{SURFACE TEXTURING}

Surface texturing has been achieved first using photolithography to define the textured patterns followed by reactive ion etching pattern transfer process as illustrated in Fig.1.

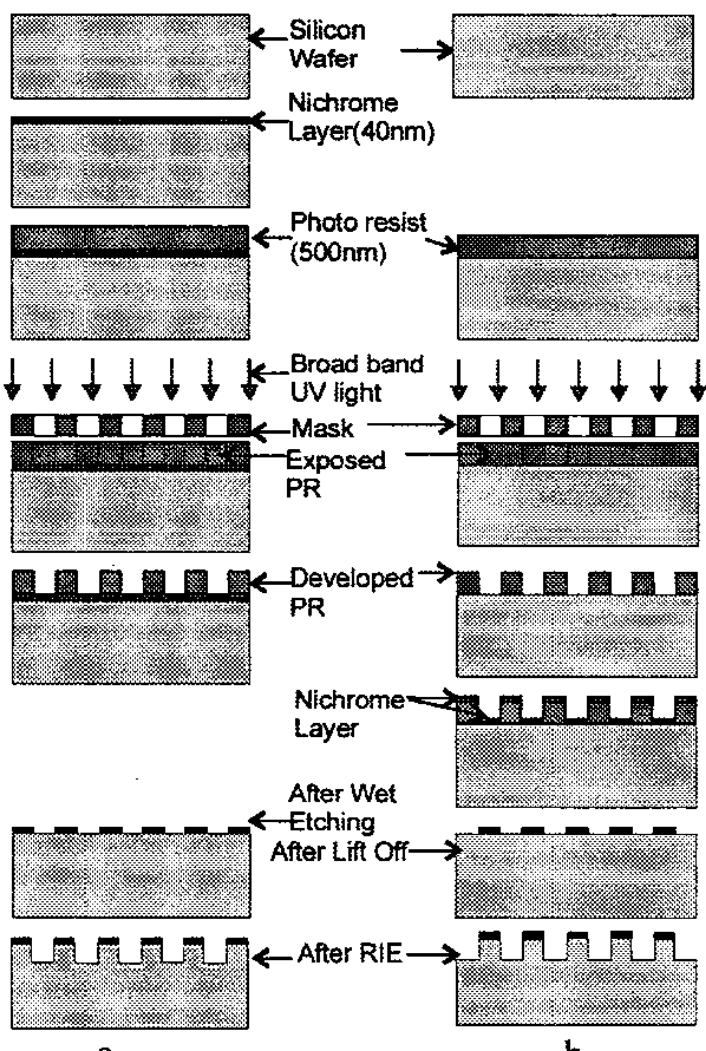

a

b

Fig.1. Schematic diagram of the pattem definition and transfer processes. (a.) Subtractive pattem transfer scheme used for the hole type structure. (b) Additive (lift-off) technique used for the column(cone) type structure 


\section{Pattern definition}

A $500 \mu \mathrm{m}$ thick single crystal silicon cut to $20 \times 20 \mathrm{~mm}[p$ type, $-1 \Omega . \mathrm{cm},(100)$, one side polished] was used as substrates. Photolithography technique was performed using a conventional mask aligner with mercury arc lamp characterized by a broadband illumination with dominant wavelength between 313 and $600 \mathrm{~nm}$ to define the patterns. Exposure time was held $35 \mathrm{sec}$ in all experiments.

A Chrome on Glass mask (arrays of $3 \mu \mathrm{m}$ holes in $4 \mu \mathrm{m}$ pitch, hexagonally arranged) was used as the lithography mask. A commercially available g-line photoresist (Shipley S-1805) has been used for pattern definition. All samples were dip-developed in Shipley MF320 developer at 3:1 dilution in deionised water for $10 \mathrm{~s}$. We employed subtractive (etching) technique for making hole type patterns and an additive (lift-off) technique for making column type patterns. For lift off process $40 \mathrm{~nm}$ of $\mathrm{NiCr}$ was evaporated on top of substrates.

The steps used in the fabrication of the hexagonally arranged holes structure are shown in Fig.1(a) and those for columns structure are shown in Fig.1(b).

\section{Reactive lon Etching Processes}

An Oxford PlasmaLab80 Reactive Ion Etcher with cryogenic electrode has been employed for this purpose.

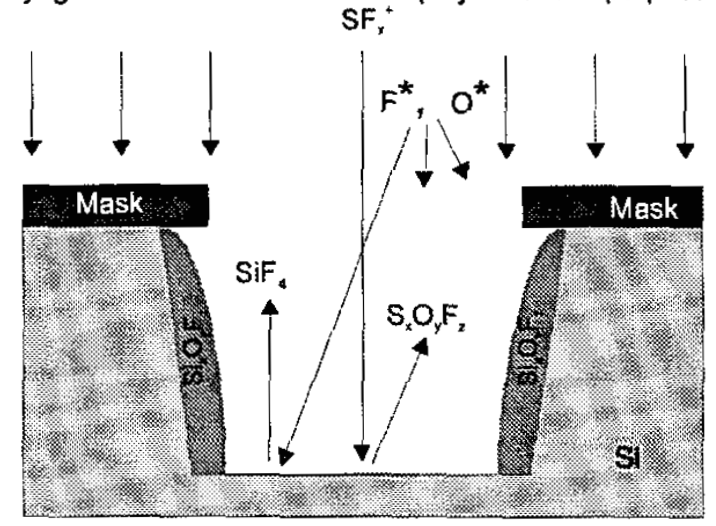

Fig.2. schematic diagram of the etch mechanism of $\mathrm{SF}_{6} / \mathrm{O}_{2}$ gas system.

Principle of Si etching using $S F_{6}$ plasma is shown in Fig. 2. In $\mathrm{SF}_{6} / \mathrm{O}_{2}$ plasma, $\mathrm{SF}_{6}$ produces the $\mathrm{F}^{*}$ radicals for the chemical etching of $\mathrm{Si}$ by forming volatile $\mathrm{SiF}_{4}$. Oxygen creates the $\mathrm{O}^{*}$ radicais to passivate the Si sode wall surfaces with $\mathrm{Si}_{x} \mathrm{O}_{y} \mathrm{~F}_{z}$ which helps to control etch profiles

\section{a. Hole structure formation}

Exposed and developed samples with $3-4 \mu \mathrm{m}$ hole structure defined by wet etching the metal $(\mathrm{NiCr})$ mask were subjected to a 30 minutes etch at a $\mathrm{SF}_{6} / \mathrm{O}_{2}$ flow rate of $90 / 10 \mathrm{sccm}$ (where sccm denotes cubic centimetres at STP). An RF power of $150 \mathrm{~W}$ ( Power density of
$0.34 \mathrm{~W} / \mathrm{cm}^{2}$ ), etch pressure of $70 \mathrm{~m}$.Torr and temperature of $173 \mathrm{~K}$ were used for the hole and pillar structure. This sample was over etched to eliminate the remaining flat surfaces.

The final textured surface of hole type structure is shown in Fig.3. after the dry etch processes.

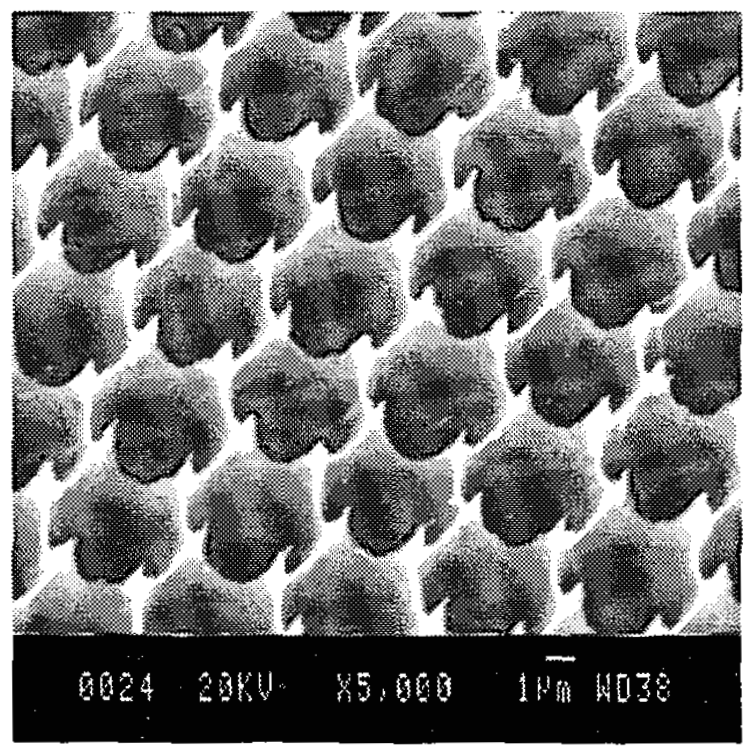

Fig. 3. SEM photograph of hole type structure. Holes are 7-8 $\mu \mathrm{m}$ depth and in $4 \mu \mathrm{m}$ pitch.

\section{b. Column structure formation}

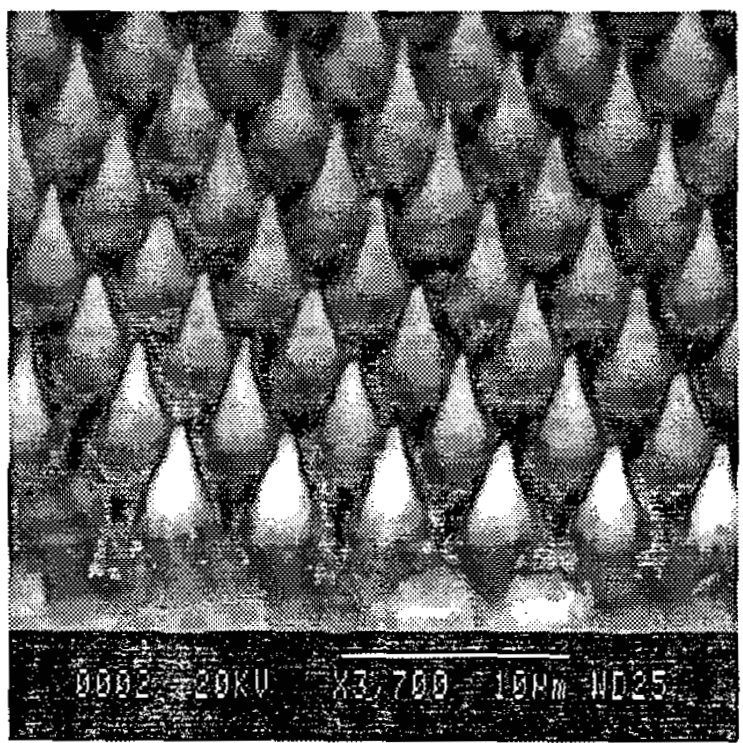

Fig .4. SEM photograph of cone type structure. Cones are 6-7 $\mu \mathrm{m}$ height and in $4 \mu \mathrm{m}$ pitch. 
A silicon wafer with arrays of $3-4 \mu \mathrm{m} \mathrm{NiCr}$ dots which were transferred using lift off technique was subjected to a RIE treatment similar to that described in (a).

The final textured surfaces of column type are shown in Fig.4. after the dry etch processes. The column structures were ended up with cone structure due to our intentionally over etching.

\section{c. Black silicon formation}

In this process no intentional mask is used. The black silicon texturing is based on local and regenerating oxide masking and therefore inhomogeneous etching. Initially the surface is covered with native oxide. This masking layer is not removed homogeneously, but perforated first. Unmasked spots are etched and pyramid to needle like structures are formed (depending on the degree of isotropy of the etch process) [8]. The walls of the structures are covered with adsorbed $\mathrm{Si}_{x} \mathrm{O}_{y} \mathrm{~F}_{z}$ and are therefore somewhat protected against etching as shown in Fig.5. The directed ion bombardment in RIE removes silicon as well as the adsorbed film. With the right choice plasma parameters the regeneration of the adsorbed masking layer during the etch is just sufficient to maintain a kind of randomly perforated mask.

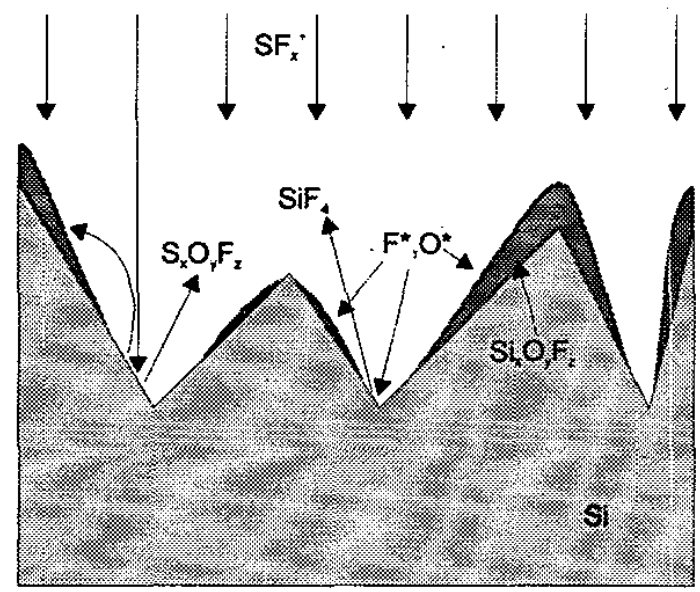

Fig.5. Schematic diagram of the formation of Black Silicon or random pyramids. Shaded areas are $\mathrm{Si}_{x} \mathrm{O}_{y} \mathrm{~F}_{z} .[9]$

An unmasked silicon wafer was dry etched for 10 minutes at a SF$/ \mathrm{O}_{2}$ flow rate of $90 / 25 \mathrm{sccm}$ at $\mathrm{RF}$ power of $200 \mathrm{~W}\left(0.45 \mathrm{~W} / \mathrm{cm}^{2}\right)$ and temperature of $173 \mathrm{~K}$. The resulting SEM image of the textured surface is shown in Fig.6. High oxygen flow rate and high power were needed for the formation of black silicon. The surface was investigated using Atomic Forces Microscope and Surface Mean Roughness was calculated as $517 \mathrm{~nm}$ while the tallest structures ware as high as $4 \mu \mathrm{m}$ in size.

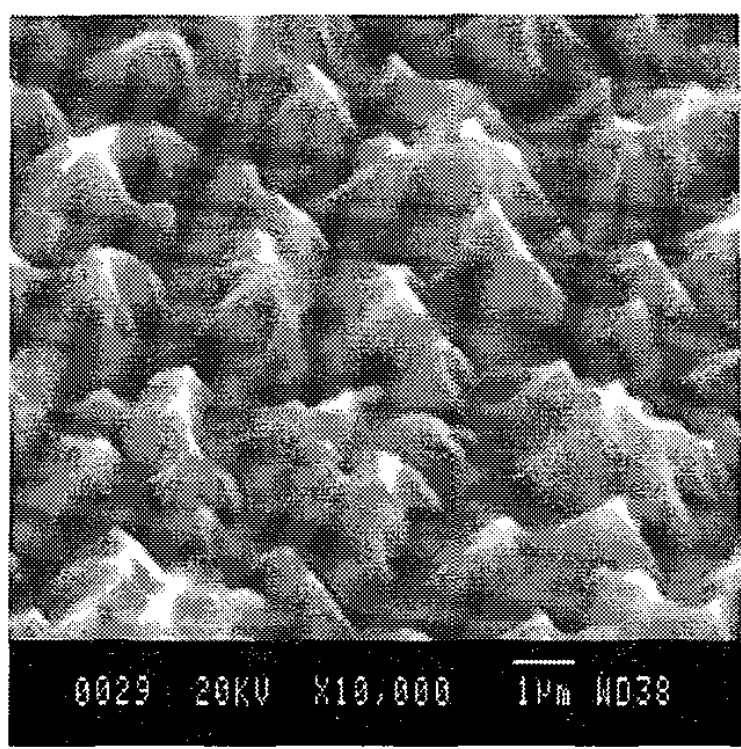

Fig.6. SEM photograph of black silicon.( No intentional mask is used). The bright areas represent highest points and dark areas represent lowest points.

\section{REFLECTANCE MEASUREMENT} Diffuse reflection of planer silicon
and textured silicon surfaces

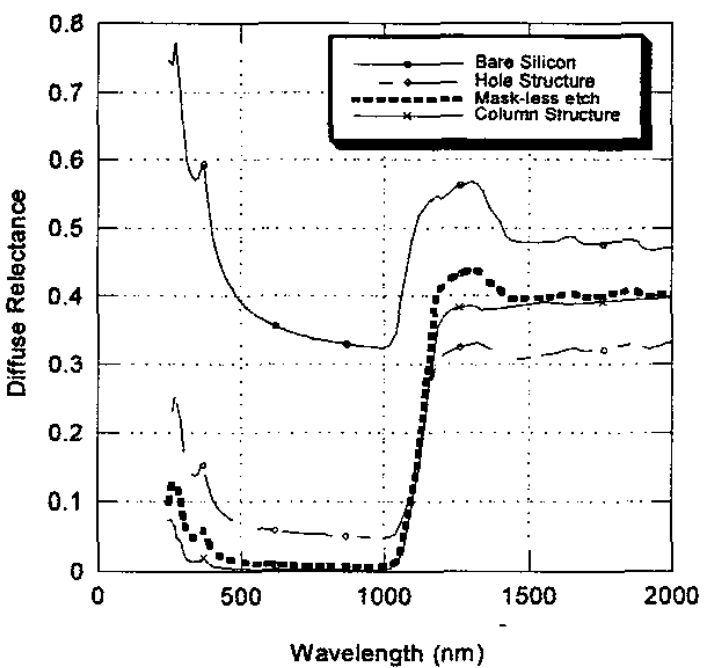

Fig.7. Diffuse refiection of planer silicon and the textured surfaces of Hole type structure, Column type structure and Mask-less etched structure. 
The diffuse reflectance of each of the four samples was measured using a purpose built integrating sphere attachment of a high accuracy spectrophotometer. The measurements were made against a pressed halon reference standard and are accurate to better than $1 \%$ over most of the visible wavelength range. For uniformly treated samples, the values obtained should therefore represent the absolute reflectance of the sample surface, at least in the region of strong absorption of Si up to $\sim 1000 \mathrm{~nm}$. For values above that wavelength, the samples become transparent and the measured reflectance then depends on the sample backing used.

Figure 7 shows the measured diffuse reflectance as a function of the wavelength. It can be seen that in all three types of textured surfaces the reflection decreases at wavelengths from 250 to $2500 \mathrm{~nm}$. In particular, at wavelengths from $250 \mathrm{~nm}$ to $1000 \mathrm{~nm}$, which include the visible region, the reflection decreased drastically compared with that of the polished silicon surface as expected.

The reflectance from the surface of the cone structure was less than $0.4 \%$ at wavelengths from $400 \mathrm{~nm}$ to $1000 \mathrm{~nm}$ and showed a minimum of $0.29 \%$ at $1000 \mathrm{~nm}$ which is much less than that obtained for hole structures. The untreated silicon wafer shows a reflectance of approximately $40 \%$ at wavelengths from $400 \mathrm{~nm}$ to $1000 \mathrm{~nm}$ and shows a minimum of $32 \%$ at $1000 \mathrm{~nm}$.

In comparison the reflectance of the hole structure was around $6.8 \%$ at wavelengths from $400 \mathrm{~nm}$ to $1000 \mathrm{~nm}$ and showed a minimum of $4.8 \%$ at $1000 \mathrm{~nm}$.

Even though the hole structure shows higher reflectance than that of column structure at wavelengths from $400 \mathrm{~nm}$ to $1000 \mathrm{~nm}$, it exhibits approximately $8 \%$ less reflectance than that of column structure at wavelengths higher than $1000 \mathrm{~nm}$ but this may be due to the backing layer used in our measurements.

The reflectance of the mask-less etched surface was less than $1.4 \%$ at wavelengths from $400 \mathrm{~nm}$ to $1000 \mathrm{~nm}$ and showed a minimum of $0.8 \%$ at $1000 \mathrm{~nm}$.

\section{CONCLUSION}

A Reactive Ion Etching process has been developed for surface texturing. Three structures have been compared for surface texturing; column structures, hole structures and mask-less etched structures and showed measured reflectance of less than $0.4 \%, 6.8 \%$ and $1.4 \%$ respectively at wavelengths from $400 \mathrm{~nm}$ to $1000 \mathrm{~nm}$. This crystal orientation-independent texturing can be used both for monocrystalline and multicrystalline solar cells without introducing significant damage as evident from a Sub-micron channelling contrast microscopy (CCM) performed on these samples. The advantage of using RIE texturing is that RIE is a parallel, high throughput process compared to the laser texturing which requires serial process.

\section{ACKNOWLEDGMENTS}

The authors would like to acknowiedge the contributions from other members of the Nanostructure Engineering Science and Technology Group, Department of Electrical and Computer Engineering. University of Canterbury. This research is supported by The New Economy Research Fund, Foundation for Research, Science and Technology, New Zealand, contract No. UOCX-9905

\section{REFERENCES}

[1] M.A. Green, Solar Cells: Operating principles, Technology and System Applications, vol.1. Kensington new South Wales: University of New South Wales, 1982.

[2] S Narayanan, "High efficiency polycrystalline silicon solar cells" PhD dissertation, Univ. of New South Wales, Sydney, Australia, 1989.

[3] P.Path, G.Wileke, E.Bucher, J.Szlufcic, R.M Murti, K.De Clercq, J.Nijs, and R.Mertens, "Mechanical wafer engineering for high efficiency Solar Cells: An Investigation of the induced Surface Damage" in Proc. $24^{\text {th }}$ IEEE Photovoltaic Specialist Conf., 1994, pp. 1347 1350 .

[4] R.R.Bilyalov, L. Stalmans, L.Schirone, et al., "Use of porus silicon antireflection coating in multicrystaline silicon solar cell processing". IEEE Trans. Electron Devices 46, 1999, pp. 2035-2040.

[5] H. Jansen, M.D. Boer, R. Legtenberg, et al., "The black silicon method: a universal method for determining parameter settings of a fluorine-based reactive ion etcher in deep silicon trench etching with profile control", Joumal of Micromechanics and Microengineering 5, 1995, pp. $115-120$.

[6] J.Zhao, A.Wang, M.A.Green, et al., "19.8\% efficient "honeycomb" textured multicrystalline and $24.4 \%$ monocrystalline silicon solar cells", appl.Phys.Lett.73, and 1998, pp.1991-1993.

[7] E.J Teo, M.M.Alkaisi, A.A. Bettiol, T.Osipowicz, J.Van Kan, F.Watt, Andears Markwitz, "Sub-micron channelling contrast microscopy (CCM) on reactive ion etched deep silicon microstructures." Nuclear instruments and Methods in Physics Research B 190, (2002) 339-344.

[8] T Wells, M.M El-Gomati and J.Wood, "Low temperature reactive lon etching of silicon with $\mathrm{SF} 6 / \mathrm{O} 2$ plasmas", J.Vac, Sci Technol. B 15, 1997,pp.339.

[9] Martin Schnell, Ralf Ludemann, Sebastian Schaefer, "Plasma surface texturization for multicrystalline silicon solar celis", Proc. $28^{\text {th }}$ IEEE Photovoltaic Specialists Conf. 2000, pp. $367-370$. 